\title{
Cultural and Social Identity in Clothing Matters "Different Cultures, Different Meanings"
}

\author{
Fatjri Nur Tajuddin ${ }^{1}$ \\ ${ }^{1}$ Masters Student at the Department of Social and Cultural Anthropology,Eberhard Karls \\ Universität Tübingen.
}

\section{ARTICLE INFO}

Keywords:

Clothing; Identity;

Symbol; Social

Phenomena; Human

Culture

\begin{abstract}
This article is concerned with the matters of clothing as a cultural and social identity which is understood to be a part of symbol that can explain a person's identity. This has been felt by humans since ancient times and developed along with the development of human culture and civilization. From this point of view, we can learn things related to clothing. Every country or region has different characteristics as an identity that is manifested in the form of traditional or distinctive clothing, customs, folk songs, and language. This can be used as a characteristic of every country or region that generally aims to be easily recognized by the wider community. One of the identities of a region is the form of clothing or clothing used. The need to know the characteristics of other regional or country cultures is very important in adding insight as well as citizens can recognize the culture or identity of other regions or countries so as not to be blind in insight and not favour selfishness to recognize the identity of other regions or countries. So many regions and countries have different characteristics. Possibly there are similarities that originate from where they came from like if a country once united and then divorced to establish its own country, this can create equality.
\end{abstract}

\section{Introduction}

Clothes are things that cannot be separated from humans and become an important part as one of the basic needs. In a book written by Malcolm (2002), it was explained that clothing can function as a communication tool for the identity, customs, and individual nature of its use. A person's dress style is influenced by many things such as culture, values inherited by community groups as well as family, environment, media, fashion trends, and personal character. All of them give reference to how to dress and shape their preferences.

With the development of Fashion, every human being, especially women, has tried not to be left behind. Starting from children to adults is very concerned about the development of the Fashion. 
And now, the development of the fashion world has experienced a period of rapid revolution in various places. Clothing is now a basic need for humans besides food and shelter. Clothing is needed to protect the body. Clothing is everything from head to toe that gives the wearer comfort. Clothing is not limited to the fabric problem that is worn by someone, but design creations that are deliberately chosen after adjusting to one's circumstances. Therefore, they will not wear clothing without understanding the self-disclosure based on habits or laws that apply in the surrounding community.

\section{Identity and Symbol}

In a general perspective, cultural values are expressed using symbols, it is necessary to see symbolic and cultural relations. Symbol is one of cultural productions or conversely the symbol can produce a culture because symbols and culture are two things that have reciprocity. Culture itself consists of ideas, symbols and values as the work of human behaviour, so close is human culture with symbols, that humans can also be called symbolic beings.

One of the most famous definitions in Modern times was given by Whitehead (1928) in his book Symbolism, he said that human mind functions symbolically if several components of its experience arouse awareness, trust, feelings, and images of other components of its experience. Previous component devices are symbols and component devices which then form the symbol meaning. Organic function which causes the transition from symbol to meaning will be called a reference.

Based on these conclusions, symbols are something that is present and exists in human life, even in human life is always associated with symbols and symbols created from human experience and by itself that meaning is built on human experience, but that meaning far exceeds just human experience, where it relates to things that are transcendent. The theory of personality by Herre (2003) also explains that it contains an arrangement of dimensions that distinguishes the ways of oneself arranged and presented. Harre describes the dimensions of personality are appearance, realization, and intermediary. Appearance refers to whether an aspect of oneself is displayed in general or is still regarded as something personal. Realization of resources is the level at which self-characteristics are believed to originate in the individual or from the group where the self becomes a part. Intermediaries are levels of active power that are inherent in themselves. Active elements such as talking, driving, passive elements: listening. In the simplest sense we mean by cultural identity is the breakdown of characteristics or characteristics of a culture that is owned by a group of people we know the limits when compared to the characteristics or characteristics of others.

Burke (1969) said that determining cultural identity is highly dependent on language, as language representations explain all the facts of all identities detailed then compared. Therefore, it can be concluded that if we talk about identity then we only talk about certain characteristics and those characteristics are indicators for getting to know other groups so that it is easier for us to communicate with them. Conversely, if we talk about cultural patterns, what we emphasize is how an identity is formed from certain views and ideas that in turn guide them. So that identity is static, and cultural patterns are living things. So the symbol can lead to an object, an event, or someone in the world that is limited by the five senses or can point to another world and to the content imagined. The symbolic forms include body and food, soil, clothing, light and darkness, fire and blood water and sacrifice. In this section will be more focused on the body as a symbol. To arrive at the body as a symbol, it is necessary to know the basic understanding of the body. 


\section{Clothing as a Symbol of Culture (Fashion as Self-Imaging)}

In the process of modernization it can hardly be limited in scope and problem, from social, economic, cultural and so on. The clothes worn by someone have hidden meanings and messages, even clothes no longer only function as protectors but also to show their social status in society. If you look at the traditions and customs of different regions, you can also know that clothing and its use is growing, namely clothing that is used for everyday activities and clothing that is worn on certain events, complete with veiled messages on the clothing.

On the other hand, fashion can also distinguish one's position and status in society. Not to mention the makeup that is always present. In general, makeup done by many people is inseparable from the outlook on life and the prevailing beliefs in society. We can pay attention to this in the behavior of people in the interior who decorate their ears to large holes. The foregoing is evidence of how closely the influence of cultural values, customs and views of life on the fashion form that develops in the community in the area. Clothing was originally designed as a way to protect ourselves from cold and other elements. Since that time period, clothes have developed not only become an extension of our personality, but as a status symbol which is better than individuals who wear fine cloth and jewellery rather than poor. Today, while clothing that is still used as a status symbol, it is easier to create a higher-status appearance by using the clothes you wear to accentuate your body in a way that reflects people with higher status.

How to dress, dress up, and physical appearance is often the basis for first impressions, which are relatively long-lasting, even the glasses can influence other people's perceptions of usage. Sometimes we dress to impress others, to be more like them, or if we wear clothes that are contrary to the norms held by a group of people to express our rejection of their values. Clothing is a part of unity that cannot be separated from social life. In the personal dimension, clothing becomes a medium to explore expressions and ideas that sometimes appear in abstract forms. Through the socio-cultural dimension, clothing is used as a medium of communication, promotion, and even the formation of ideology. Various problems that arise in social life can be reflected through clothing products, so that the formulation of communication between users, connoisseurs, and clothing creators is formed systematically. Clothing products as a visual manifestation of cultural products are often used as markers and social identities for the social community. Symbols of discrimination, adoration, characterization and blasphemy appear along with the circulation of clothing products. Discourse on clothing is not a simple matter in the social cultural context; religion, morals, ethics, and art. This paper, in its limitations, with semiotic, communication, aesthetic and religious perspectives, describes the socio-cultural dimension of dress style.

Clothing in the area of the formation of personal or community ideology is a stylish dimension. This stylish order and guidance is often interpreted as an attempt to express desire and recognition of identity in the context of social life. Uncontrollable expression in style, encouraging some personalities to provide comfortable or not-appropriate clothing boundaries, or not, to be displayed to the general public, at least in their social community. Limitation of this style of dress, which is often seen as irregularity to be accepted and placed in a particular culture. Contradictions and questions related to religious, moral, and ethical values in responding to art products "clothing" appear in a different manner. On the other hand, the occurrence of distortion of the meaning of clothing as a basic need becomes clothing as a luxury need for style. Of course, it is not immediately the clothes in question as a source of complexity, there are media roles "advertisements", industries "creators", communities "users and creators", as well as social 
institutions "government and its tools" that shape the turn of clothing into products that regulate its users.

\section{Changes in How to Dress "A Cultural Phenomenon"}

The ability of humans to develop equipment and how to control technology is possible because of the symbolic power that is not possessed by other creatures. By using symbols that are given meaning, humans can convey their thoughts and knowledge. Clothing is one of the cultural expressions. Therefore, when someone is dressed, we can judge a culture that is in him or clothing is a form of intercultural communication because clothing reflects a culture.

Dress ethics is also interpreted as a reflection of ourselves in interpreting the meaning of ourselves in dress that is polite and good, if we wear polite clothing means we have good ethics, if we wear clothes that are not good, it means that we are stamped with bad ethic, let us go highend clothing ethics that are polite and kind. Apart from functioning as protective clothing, it is also a form of communication, as stated by Adler and Rodman (1999) that clothing can be used to display economic status, education, social status, moral status, athletic ability, funds know interest, belief systems (politics, philosophy and religion, and level of satisfaction. Clothing that is as a support for our daily appearance will provide an assessment for those who see it.

Fashion is a biological need and cultural needs, even now it has developed into a life style needs. Clothing is not only a tool to protect the body from the influence of the surrounding air, but is a means to express themselves to the wearer. The development of fashion is increasingly rapid, and the rotating fashion cycle alternates, the fashion mode received by the public will become a fashion trend, while the mode that is not accepted will be ignored. Technological developments that are increasingly globalized make fashion styles grow rapidly, so that the mode that is popular in other countries can be immediately adapted also by the people through modernization in the field of technology called the internet. Technology modernization has a great impact on other sectors including clothing.

Socio-cultural changes that occur in society, such as changes from traditional society to modern, it turns out that not all people can accept it, but there are some people who cannot accept it. Communities that cannot accept change usually still have a traditional and thick mind-set, so they are not easily influenced by new things, especially those related to beliefs or belief systems that have been believed for generations. Traditional communities tend to be more difficult to accept foreign cultures that enter their environment, but there are also people who easily accept foreign cultures in their lives. This is due to the element of foreign culture that usually brings great convenience and benefits to their lives, or elements of culture that easily adjust to the state of the people who receive these elements.

\section{Ethnographical Examples "Hijab in London" and "Blue Jeans Conquered the World"}

Hijab trends are an important part of civilizing hijab in socio-cultural life. Headscarves in the arena of Islamic culture experience a distortion of meaning, as a result there is an uniformization of the use of the hijab, modification of the hijab, and creating a variety of reciprocal communications in it. The headscarf cannot be used as a sign of one's obedience or devotion; not a big hijab or a small hijab, even if someone is wearing a headscarf or not. The headscarf ideology is not only for demonstrating devotion, there is construction (other meanings) built up in it, as trends, culture, identity, means of communication, and the role of mass media culture. 
The acceptance or rejection of hijab can be seen from the example as research conducted by Tarlo (2007) in London about the potential for changes in Hijab among London's urban Muslim communities. In terms of hijab, it certainly has meaning and definitely affects meaning that is contained in it, because hijab is understood not only physical changes but also changes in attitude as to be more religious. From the research conducted, it can be seen that (1) how individual decisions to wear hijab may come about through exposure to a hijab-wearing lifestyle which is just one of a large repertoire of ways of being open to both Muslims and non-Muslims in London who may or may not take it up for their own personal reasons; (2) it show how the adoption of hijab may come to guide or delimit a person's modes of action; for instance, Loraine can no longer go to the salon, a trivial example, but others will follow; and (3) it shows how the visual presence of one person's hijab may have effects on the actions of others.

From my point of view, they want to keep the hijab tradition to cover the body in order to avoid the view of men as part of showing their pious to the God, by using a simple hijab. On the other hand, the development of urban life affects that, hijab users want to offer to the world that hijabs are not necessarily traditional; they can also interact in social or public environments safely, and follow modes by modifying the hijab, but it the end, it will change the meaning of the hijab. The problem is the way of wearing hijab, because if I can see that the perspective slowly shifted. While many Muslim women are no longer wearing a niqab (a woman Muslim clothes that cover their body and face), merging with people in public, their conservative counterparts start peering into popular fashion stores, partly because they are driven by their trendy Muslim friends. But the old stereotype is still hard to abandon.

In addition, as another example, how blue jeans can be accepted in various circles throughout the world. Miller and Woodward (2012) conducted research on blue jeans. To prove it, Miller travelled through various countries in the world, from the Philippines to Brazil. As a result, he found that almost half of the population in each country he visited wore jeans on certain days. At present, jeans are the prima donna of the fashion world worn by young, middle-aged and parents, both those who are body-shaped and loose. In fact, the famous designers of the world did not forget to include clothing made from denim to their collections like Tommy Hilfiger, Calvin Klein, Victoria Beckham and Giorgio Armani.

\section{So, What to Wear?}

Explaining one's identity is closely related to the culture and customs in which a person lives and interacts in life. Clothing as a cultural diversity should be taken into account. Clothing is an expression, image and personality of a culture, because from clothing can be reflected the norms and cultural values of a nation. Clothing tends to be inseparable from the culture of society, because it is influenced by habits, customs that exist in society.

The different clothing between one region and another, due to human culture in each region tends to be different, which is influenced by the surrounding environment. The difference in clothing in each region is because each region has customs, habits, ways of life that can be different from one another, and different socio-cultural environments.

\section{Conclusion}

In relation to dress, it can be interpreted that dress ethics is a science that considers how a person can take an attitude in dress about the model, colour, pattern or motive which is appropriate in accordance with the opportunities, conditions and time and norms that apply in the community. 
Dressing aesthetics can be interpreted as a field of knowledge that discusses how to dress in harmony with one's body shape and personality. Dressing beautifully and in harmony that applies aesthetic values means you have to be able to choose the model, colour and style, texture, which suits the user.

Clothing has a variety of explicit and implicit meanings. Clothing is a form of imitation of one's social body, so that the limitations of each person's personal comfort are different. A piece of clothing can describe a structure of social life, ideology, history, class, community, and identity. The ideology of religion in clothing, regarding moral and ethical issues, is a rule or law regarding how to dress according to the conditions of space, place, and time, which need to be understood and implemented. Supposedly, the freedom in creating clothes, not forgetting the relationship of clothing with the surrounding social environment, because clothing as a basic necessity is included in the public domain, so that social welfare is still needed. In the end, clothing is still a part of inanimate objects, social construction in it, which makes clothing a product that has a lot meaning.

\section{Acknowledgment}

I thank Allah for everything in my life and also for my all family In Jeneponto, Indonesia, Especially for my parents Tajuddin and Fatmawati. This article is drawn was funded by the LPDP Scholarship (Indonesia Endowment Fund for Education) Ministry of Finance, Republic of Indonesia. I am extremely grateful for this support. I should also like to thank my supervisor Prof. Gabi and all lecturers in the Department of Social and Cultural Anthropology, University of Tuebingen for the help and guidance.

\section{References}

1. Adler, Ronald B and George Rodman.: Understanding Human Communication, Oxford University Press, 1999

2. Barnard, Malcolm.: Fashion as Communication, Routledge, 2002

3. Burke, Kenneth.: A Rhetoric of Motives, University of California Press, 1969

4. Herre, Rom.: The Self and Others: Positioning Individuals and Groups in Personal, Political, and Cultural Contexts, Greenwood Publishing Group, 2003

5. Miller, Daniel and Sophie Woodward.: Blue Jeans: The Art of the Ordinary, University of California Press, 2012

6. Tarlo, Emma.: Hijab in London: Metamorphoses, Resonance and Effect. Journal of Material Culture, 2008

7. Whitehead, Alfred North.: Symbolism, Cambridge University Press, 1928 
European Journal of Behavioral Sciences, 1(4):67-72, 2018 